\title{
REFLEXÕES SOBRE O MÍNIMO EXISTENCIAL DA EMPRESA
}

\author{
Denise Lucena Cavalcante \\ Pós-Doutora em Direito pela Faculdade de Direito de \\ Lisboa (2012). Doutora em Direito pela Pontifícia \\ Universidade Católica de São Paulo (2002). Mestre em \\ Direito pela UFC (1993). Especialização em Direito \\ Tributário Internacional pela Universidade de Salamanca- \\ Espanha (2001) e pela Universidade Austral - Argentina \\ (2004). Professora Associada IV da graduação e pós- \\ graduação da Universidade Federal do Ceará (UFC). \\ Professora Titular da graduação e pós-graduação do \\ Centro Universitário 7 de Setembro (UNI7). Líder do \\ Grupo de Pesquisa Tributação Ambiental. \\ deniluc@ fortalnet.com.br

\section{Mariana Bezerra Muller} \\ Mestranda pelo Programa de Pós-Graduação em Direito \\ do Centro Universitáio 7 de Setembro (UNI7). Bacharel \\ em Direito pela Faculdade Maurício de Nassau - Natal. \\ marianabmuller@gmail.com
}

RESUMO: O artigo versa sobre a ampliação do princípio do mínimo existencial para as pessoas jurídicas no Brasil, garantindo que a carga tributária não inviabilize sua atuação no mercado. O debate inicia-se com os direitos fundamentais para as pessoas jurídicas, com foco nos limites ao poder de tributar previstos na Constituição brasileira. Os princípios da capacidade contributiva, da isonomia e da proibição do confisco servem de base para proteger a atuação empresarial e garantir o patrimônio mínimo. Defende-se a necessidade de respeito ao mínimo existencial da empresa, viabilizando, assim, a livre concorrência e a espontânea iniciativa.

PALAVRAS-CHAVE: Tributação. Capacidade contributiva. Mínimo existencial da empresa.

\section{Reflections on the existential minimum of the company}

\begin{abstract}
This essay deals with the expansion of the minimum existential principle for legal entities in Brazil, ensuring that the tax burden does not make it impossible to act in the market. The debate begins with the issue of fundamental rights for legal entities, focusing on the limits to the power to tax foreseen in the Brazilian Constitution. The principles of contributory capacity, isonomy and prohibition of confiscation serve as a basis for protecting business performance and guaranteeing minimum assets. It is defended the need to respect the minimum existential of the company, thus enabling free competition and free initiative.
\end{abstract}

KEYWORDS: Taxation. Contributory capacity. Existential minimum of the company.

\section{CONSIDERAÇÕES INICIAIS}

Comumente, a expressão "direitos fundamentais" está vinculada ao cidadão, sendo, por vezes, esquecida a sua aplicabilidade também às pessoas jurídicas, na medida de sua natureza e da sua devida capacidade de exercê-los. 
Parte-se aqui da premissa de que a pessoa jurídica também é titular de direitos e garantias fundamentais e, na qualidade de contribuinte, está protegida pelo rol de princípios constitucionais tributários expressos no art. 150, da Constituição da República Federativa do Brasil, oportunamente, denominados "das limitações do poder de tributar".

Por tal feita, é necessário que se levem em conta a igualdade e a capacidade contributiva como fatores limitadores da tributação, de modo a evitar que os tributos tenham efeito confiscatório e, ao mesmo tempo, impedir que se atinja o patrimônio mínimo do contribuinte.

Nesse sentido, nenhum óbice existe para a compreensão de que a personalidade é um dado jurídico e, se a lei achou por bem atribuir a condição de sujeito de direitos às empresas, pois, sendo estas titulares de direitos e obrigações, serão alvo de tributação e, consequentemente, da proteção ao excesso de tributação. Com efeito, a capacidade contributiva é um direito fundamental inerente à personalidade, razão por que é amplamente aplicável às pessoas jurídicas.

Seguindo esta linha, o Estado tem de observar que, consoante ocorre com as pessoas físicas, as jurídicas necessitam de um patrimônio mínimo para lhes garantir a existência como empresas e a manutenção de sua atividade produtiva.

Assim, mostra-se plenamente cabível a ideia de respeito ao mínimo existencial das organizações negociais, sendo razoável sua aplicação para que se evite uma tributação excessiva onde não exista capacidade contributiva.

\section{DiREITOS FUNDAMENTAIS EXTENSIVOS ÀS PESSOAS JURÍDICAS}

Os direitos fundamentais são fruto do estabelecimento de uma luta histórica por parte da população, que via a necessidade de ter seus direitos respeitados ante a atuação do Estado. A incorporação formal de direitos e garantias fundamentais na Constituição brasileira visa a assegurar às pessoas uma atuação livre de abusos e arbitrariedades estatais e, ao mesmo tempo, um respeito por parte do Estado às mais diversas configurações de liberdade.

De início, cabe determinar que os titulares dos direitos fundamentais, no âmbito de uma relação jurídica, são aqueles que podem exigir o cumprimento, o respeito ou a proteção dos direitos garantidos. Assim, ante qualquer ameaça de privação, na maioria das vezes, tal circunstância exige a atuação do Estado. Como salienta Robert Alexy (2008, p. 456), o direito de defesa existe em face do Estado e a que ele se abstenha de intervir; direito à proteção é um direito em face do Estado e a que ele zele para que terceiros não intervenham.

Desde que promulgada a Constituição da República Federativa do Brasil, em 1988, os direitos fundamentais previstos nela são de incidência inquestionável quanto às pessoas físicas. Outrora, quando se tratava acerca de pessoas jurídicas, ao contrário do que ocorreu com a Lei Fundamental alemã, que reconheceu expressamente a validade dos direitos fundamentais para as pessoas jurídicas em seu artigo 19, III $^{1}$, essa previsão não foi expressa na Carta Magna pátria e, por tal razão, ficou dita função a cargo da doutrina e da jurisprudência.

Neste sentido, Gilmar Mendes e Paulo Branco assim se expressam:

1 Art. 19, (3): Os direitos fundamentais também são válidos para as pessoas jurídicas sediadas no país, conquanto, pela sua essência, sejam aplicáveis às mesmas. [Tradução livre]. Disponível em: <https://www.btg-bestellservice.de/ pdf/80208000.pdf>. Acesso em: 19 mar. 2018. 
[...] não há, em princípio, impedimento insuperável a que pessoas jurídicas venham, também, a ser consideradas titulares de direitos fundamentais, não obstante estes, originalmente, terem por referência a pessoa física. Acha-se superada a doutrina de que os direitos fundamentais se dirigem apenas às pessoas humanas. (2015, p. 171).

Os entes coletivos, perante as novas facetas dos direitos fundamentais, são reconhecidos como merecedores de proteção, conforme se pode analisar na lição de José Afonso da Silva (2017, p. 194):

\begin{abstract}
[...] a pesquisa no texto constitucional mostra que vários dos direitos arrolados nos incisos do art. $5^{\circ}$ se estendem às pessoas jurídicas, tais como o princípio da isonomia, o princípio da legalidade, o direito de resposta, o direito de propriedade, o sigilo de correspondência e das comunicações em geral, a inviolabilidade do domicílio, a garantia do direito adquirido, ao ato jurídico perfeito e impetrar mandado de segurança. Há até direito que é próprio da pessoa jurídica [...].
\end{abstract}

O rol exposto pelo autor não é exaustivo, cabendo aplicação dos mais diversos tipos de direitos fundamentais às pessoas jurídicas, independentemente de sua localização dentro da CRFB, consoante expressa Sarlet (2009, p. 222), desde que haja compatibilidade entre tais direitos e a própria natureza da pessoa jurídica. No mesmo sentido, Dimoulis e Martins (2014, p. 4) asseveram que, para efeitos da titularidade de direitos fundamentais, as pessoas jurídicas são equiparadas às físicas, quando o exercício de um direito for compatível com as peculiaridades estruturais da pessoa jurídica.

A pessoa jurídica deve ser reconhecida como titular de direitos fundamentais. Com efeito, o intérprete da norma deve buscar não só proteger as pessoas jurídicas em si, como também amparar as pessoas físicas, já que é por meio da reunião destas que a própria ideia de pessoa jurídica é constituída, privilegiando a liberdade de associação e reconhecendo a titularidade de direitos fundamentais a todos a quem o ordenamento denominou de "pessoa".

\title{
2. MÍNIMO EXISTENCIAL DA EMPRESA
}

Uma vez compreendida a ideia de que a maioria dos direitos fundamentais se aplica às pessoas jurídicas, cumpre agora tratar sobre o respeito ao seu patrimônio perante a atuação do Estado, por meio da limitação ao poder de tributar garantida pela CRFB.

No primeiro passo, na breve análise do Estado fiscal minimalista, no qual, sob a inspiração do liberalismo, se constatava não caber ao Estado qualquer intervenção na propriedade ou na economia, os tributos denotavam apenas função arrecadatória para financiar atividades, como justiça, segurança e defesa externa, devendo o Estado se abster de invadir a vida privada, sendo incabível qualquer ato que violasse a propriedade (SCHOUERI, 2011, p. 22).

O problema surgiu com o advento do Estado social, quando o Ente estatal cresceu, com isto se ampliando, também, a necessidade de captação de recursos para se atingir inúmeras funções antes inexistentes. A realidade imposta pelo Estado social implica o aumento excessivo de tributos para manter robusto este Ser estatal e, por vezes, deixando de lado as liberdades individuais.

A insatisfação popular, em decorrência do desrespeito à propriedade privada que ocorria por parte do Estado social, fez com que fosse inaugurado o Estado democrático de Direito, com renovada ideia de limite à tributação, em demanda de evitar o caráter excessivo dos tributos e verdadeiramente inconciliável em relação à liberdade e ao respeito à propriedade privada dos contribuintes (TORRES, 2005, p. 3). 
Na organização moderna da estrutura do Estado, impõe-se a obrigação tributária aos cidadãos como meio para que este possa arcar com os seus deveres e atribuições previstas, além de atender às demandas da população. Por outro lado, busca-se o respeito aos limites da tributação, a fim de possibilitar que o cidadão viva em sociedade, com a liberdade individual preservada, evitando-se abusos por parte do Estado.

Sobre a importância dos tributos para a organização do Estado, preleciona Klaus Tipke (2002, p. 57) que, "[...] sin el Estado y los impuestos necesarios para su existencia los ciudadanos se verían sometido en breve plazo a la violencia, la arbitrariedad y la justicia privada de los demás."

A Constituição brasileira de 1988 dá a percepção da ideia de que o Brasil se encaixa na modalidade de Estado democrático de Direito e, como tal, prevê princípios liberais e direitos sociais de modo mais equilibrado.

Quando o foco é na relação tributária, a CRFB resguarda os contribuintes contra possíveis abusos por parte dos entes federativos, garantindo-lhes o direito fundamental de ver limitada a tributação por parte dos entes estatais.

Apesar de a CRFB detalhar, expressamente, os princípios gerais desde o artigo 145, existem muitos princípios que estremam a atuação tributária em toda a Constituição, havendo, inclusive, princípios implícitos que podem surgir conforme a interpretação de outros artigos.

Respeitadas as limitações ao poder de tributar, previstas na Constituição nos arts. 150152, é importante esclarecer que tal rol não é exaustivo, já que os princípios constitucionais podem surgir com a interpretação de todo o Texto Constitucional (ÁVILA, 2006, p. 53).

Não obstante, para que se entenda o mínimo existencial, é necessário primeiro cuidar do princípio da isonomia e, em decorrência deste, analisar o princípio da capacidade contributiva, buscando complementar esse exame com a abordagem ao princípio da proibição do confisco. $\mathrm{O}$ objetivo é adentrar o direito de proteção ao mínimo existencial, que tem a base no desdobramento de tais princípios, quando se refere ao Direito Tributário.

Assim, em decorrência do princípio da isonomia em matéria tributária, é que se determinam os parâmetros a serem seguidos pela tributação para tratar de pessoas físicas ou jurídicas que assumam características semelhantes.

É importante exprimir a ideia de que a igualdade está umbilicalmente ligada à capacidade contributiva das pessoas, pois somente a segunda pode operacionalizar a aplicação de tributos, exigindo a submissão a um maior ou menor ônus tributário, de acordo com a força econômica do contribuinte de suportar os encargos.

Registra-se, por oportuno, a Súmula n. 481, do Superior Tribunal de Justiça (2012) que dispõe: "Faz jus ao benefício da justiça gratuita a pessoa jurídica com ou sem fins lucrativos que demonstrar sua impossibilidade de arcar com os encargos processuais". Observa-se, também, nessa decisão o direcionamento da jurisprudência brasileira no sentido de aplicar os direitos fundamentais também às pessoas jurídicas.

\subsection{Sobre a capacidade de contribuir}

Para se obter o real significado da capacidade contributiva, é preciso enfrentar aspectos diretos tais como: quanto se pode pagar? Quanto efetivamente é pago? Qual o montante suportado pelo contribuinte? Como atingir o limite da tributação sem chegar ao confisco? 
A técnica jurídica tem de conseguir desvendar a realidade econômica das pessoas, sejam elas físicas ou jurídicas, para poder saber a resposta correta para as indagações acima e, assim, chegar o mais próximo possível da justiça fiscal (CAVALCANTE, 2014, p. 267). E, nada melhor para isto do que adotar como ponto de partida a observância do princípio da isonomia.

É certo que identificar a capacidade contributiva não é tarefa simples, porquanto a tributação deve extrair do patrimônio dos particulares recursos para agregar aos cofres públicos numerários suficientes para atender as necessidades coletivas sem, contudo, sacrificá-los ao ponto de atingir o seu mínimo existencial. Vê-se, logo, como esta fórmula é complexa, devendo ser respeitado o mínimo existencial, considerando as peculiaridades de cada contexto, pois este não é uma categoria universal (SCAFF, 2006, p.120), principalmente numa sociedade com grandes desproporções econômicas como a brasileira.

O princípio da capacidade contributiva como diretriz nas imposições fiscais é bem antigo e tem como uma das suas finalidades a redistribuição de rendas (GRUPENMACHER, 2006, p. 103), buscando equalizar a condição razoável de vida para todos, sendo o Estado o agente dessa redistribuição da renda auferida dos que possuem capacidade de contribuir, com o menor sacrifício (BRITO, 1982, p. 70).

Pressuposto básico das constituições modernas é a observância do poder econômico de cada cidadão para contribuir, conforme suas possibilidades, com as despesas estatais, resguardando sempre o mínimo de sua existência.

Cuidando do aspecto histórico do princípio da capacidade contributiva, Godoy (1999, p. 188) recorda que este é o cânone mais importante para Adam Smith, sendo que é na observância ou não deste princípio que se denomina equidade ou falta de equidade da tributação.

A técnica fiscal impõe que seja identificada a aptidão econômica do sujeito passivo para extrair a capacidade contributiva. Daí a necessidade de dotar a Administração Pública de meios hábeis para visualizar o patrimônio, os rendimentos e as atividades econômicas do contribuinte, possibilitando uma tributação mais justa, com vistas a incidir no patrimônio dos grandes grupos econômicos.

As empresas menores não podem ser sacrificadas ao ponto de inviabilizar sua existência no mercado. Medidas diferenciadas como o SIMPLES buscam atenuar as diferenças econômicas das micro e pequenas empresas, mas essa realidade ainda é insuficiente. A tributação sobre a pessoa jurídica continua muito desigual e confusa. Regras claras e mais justas são necessárias. Constata-se, pois, que a capacidade contributiva é um meio para que se atinja a justiça tributária, tendo por mister a concretização do ideal de uma tributação isonômica.

Quando se reporta ao interdito de tributação com efeito de confisco, é de fácil entendimento sua ligação com a capacidade contributiva, visto que o confisco se inicia onde termina a capacidade de o cidadão contribuir. Impõe-se, com efeito, a reflexão sobre se a exigência de um tributo não ultrapassou o patamar aceitável, de maneira a atingir em cheio o patrimônio do contribuinte, ao cúmulo de impedir o desenvolvimento pessoal e a própria atividade econômica, consoante exprime Ives Martins (2001, p. 178):

Na minha especial maneira de ver o confisco, não posso examiná-lo a partir de cada tributo, mas da universalidade de toda a carga tributária incidente sobre um único contribuinte. Se a soma dos diversos tributos incidentes representa carga que impeça o pagador de tributos de viver e se desenvolver, estar-se-á perante carga geral confiscatória, razão pela qual todo o sistema terá que ser revisto, mas principalmente aquele tributo que, quando criado, ultrapasse o limite da capacidade contributiva do cidadão. 
A capacidade contributiva e seu vínculo com a proibição de tributo, com efeito de confisco, e o próprio mínimo existencial, abrangem a renda disponível para a contribuição. De tal sorte, nenhum tributo pode atingir o mínimo existencial, pois este é anterior à própria capacidade, como também não há de ultrapassar esses limites, visto que a "[...]capacidade contributiva termina, de todo o modo, onde começa o confisco." (TIPKE; YAMASHITA, 2002, p. 67).

Conquanto o mínimo existencial não conte com previsão expressa na CRFB, sobra como mandamento implícito, pois exprime um direito fundamental dos contribuintes, que decorre não só na dignidade, mas, também, conforme demonstrado, na própria igualdade e na capacidade contributiva, encontrando sua maior aplicação nos direitos econômicos e sociais (TORRES, 2009, p. 13).

A tributação do patrimônio mínimo afeta os mais diversos tipos de direitos fundamentais e contamina a própria ideia de Estado democrático de Direito, conforme Tipke e Yamashita explicam (2002, p. 34):

O princí́io da capacidade contributiva protege o mínimo existencial. Enquanto a
renda não ultrapassar o mínimo existencial não há capacidade contributiva. O mes-
mo resulta da dignidade humana e do princípio do Estado Social. O princípio da
capacidade contributiva antes a ambos os princípios. Num Estado Liberal não é
permitido que o mínimo existencial seja subtraído pela tributação, parcial ou total-
mente, e uma compensação seja dada em benefícios previdenciários. O Estado não
pode, como Estado Tributário, subtrair o que, como o Estado Social, deve devolver.

Reconhecido como direito fundamental, o patrimônio mínimo deve ser respeitado pelo Estado, seja para a manutenção da vida digna das pessoas físicas ou para a continuidade da atividade e existência das pessoas jurídicas, em respeito à sua capacidade contributiva.

\section{EFETIVIDADE DA TEORIA DO MÍNIMO EXISTENCIAL ÀS PESSOAS JURÍDICAS}

Já consolidada a premissa de que as pessoas jurídicas são titulares dos mais diversos tipos de direitos fundamentais, Canotilho reconhece a importância destes, para que se respeite a essência do direito fundamental e da própria pessoa jurídica (1998, p. 384).

Haja vista a carência de conteúdo específico por parte da ideia de mínimo existencial, é possível induzir o argumento de que o princípio assegura aos titulares de direitos fundamentais o acesso às diversas garantias previstas na Constituição, de modo, pelo menos, essencial, existencial e não alienável, evitando-se o isolamento completo do titular aos direitos que garantem sua existência (TORRES, 2009, p. 25).

É relevante evocar a ideia de que a teoria do mínimo existencial não é restritiva, pois pode encontrar fundamentos nos mais diversos ramos do Direito e tirar sua validade com suporte na análise de vários artigos da Constituição.

Tratando sobre o alcance do mínimo existencial às empresas, destaca Denise Daniel:

Como exigência constitucional à aplicação da justiça fiscal, o mínimo isento não se
aplica apenas às pessoas físicas. Ele deve ser considerado sempre que houver mani-
festação de riqueza tributável, independentemente de quem seja o titular dessa ri-
queza. Nenhum sujeito de direito que tenha ingressos que se prestem apenas à sua
manutenção básica pode ser constrangido a contribuir com os gastos públicos.
(2006, p. 47 ).

Tal aplicação não poderia ser vista de modo diverso. A própria CRFB situa em posição de destaque a livre iniciativa, valorizando a atividade empresarial como motriz para o desen- 
volvimento econômico e social, reconhecendo a importância do cumprimento do atributo inerente à atividade empresarial, a função social da empresa, consoante explica Gladston Mamede:

\begin{abstract}
[...] o princípio da função social da empresa reflete-se tanto a favor, quanto em detrimento do empresário ou dos sócios da sociedade empresária, já que se retira deles a faculdade de conservação ou exercício arbitrário da empresa, temperando a titularidade desta com interesses públicos, o que pode levar, inclusive, à desapropriação da atividade econômica organizada ou, ainda, à sua transferência compulsória a outrem, como na hipótese de falência. Essa possibilidade, por si só, recomenda cuidado para impedir a verificação de arbítrio estatal sobre os agentes privados; a aplicação do princípio da função social da empresa não pode desrespeitar os direitos dos titulares da empresa - total ou parcialmente -, já que há proteção constitucional para a livre iniciativa (art. $1^{\circ}$, IV) e para a propriedade (art. $5^{\circ}$, XXII), embora deva essa atender à função social (art. $5^{\circ}$, XXIII), o que fecha o círculo e recomenda ao jurista prudência, bom senso, para equilibrar os valores opostos, exigindo-lhe equidade. (2015, p. 48).
\end{abstract}

Assim, o caráter dual da função social da empresa garante que o empresário se obrigue a cumprir certas exigências em nome da comunidade ou do próprio Estado que se beneficia de sua atuação. Ao mesmo tempo, a função social também tem o condão de obrigar o Estado a respeitar os direitos fundamentais da pessoa jurídica, estando, entre tais direitos, indubitavelmente, o da tributação justa.

De fato, as empresas são suscetíveis a abusos e podem ter a existência comprometida em decorrência de uma tributação desproporcional. Desse modo, o princípio da preservação da empresa, hoje abrigado junto à função social da empresa, é citado por Fachin como

\begin{abstract}
O princípio da preservação da empresa interessa ao Direito e à Economia, pela proteção que oferece à continuidade dos negócios sociais. Tal preservação da empresa tem uma notável importância. O princípio da preservação é gênero no qual a continuidade das atividades compõe espécie, e nele se encontra similitude com a guarida ao patrimônio mínimo, na hipótese inerente à manutenção do empreendimento. (2006, p. 187).
\end{abstract}

Tanto a capacidade contributiva quanto o mínimo existencial são plenamente aplicáveis às pessoas jurídicas, pois, assim como ocorre com as pessoas físicas, os entes coletivos podem ter patrimônio incompatível com a capacidade de contribuir. Tal significa expressar a ideia de ser possível inexistir lucro, pois todo o dinheiro que entra na empresa pode ser utilizado para a manutenção da própria atividade, o que é cada vez mais comum no ocorrente panorama de crise.

Releva esclarecer, por ser adequado o momento, o fato de que a capacidade contributiva da empresa difere da habilidade contributiva dos sócios que a compõem, exatamente em razão de a empresa ser portadora de personalidade jurídica própria e patrimônio independente, desde que não ocorra confusão patrimonial.

Isso posto, a atividade empresarial, com origem na própria ideia da função social da empresa, deveria não responder por encargos com o Estado, se inexistisse capacidade contributiva.

Como modo de auferir qual seria o mínimo isento a ser respeitado, deve-se considerar se existe renda além da necessária para manter a atividade empresarial de acordo com a realidade e os recursos da organização específica, já que análises fixas impedem o ente tributante de perceber peculiaridades.

No Brasil, a pessoa jurídica arca com uma complexa incidência tributária, tanto em relação às obrigações acessórias, como no concernente aos compromissos principais, com as 
contribuições decorrentes do lucro real e outros tributos originados na atividade empresarial. O faturamento é tributado, sem esquecer dos impostos sobre circulação de mercadorias e prestação de serviços, além de outras exações, podendo acarretar superposição de tributos que desconsiderem a real capacidade contributiva da pessoa jurídica.

Longe se está do parâmetro ideal. Almeja-se uma tributação que respeite a real capacidade contributiva da empresa, bem como a simplificação do sistema tributário nacional, reduzindo o número de tributos e de obrigações acessórias, com uma legislação mais clara e objetiva.

Quando se trata de pessoas jurídicas, é notória a inobservância, pela legislação vigente, ao patrimônio mínimo, fazendo com que organizações com receitas que garantem apenas o mínimo material para a sua existência e manutenção contraiam dívidas tributárias com as quais não poderão arcar, impedindo-a de prosseguir na sua atividade, em total descompasso em relação aos princípios gerais da atividade econômica.

\section{CONSIDERAÇÕES FINAIS}

Cabe reconhecer o fato de que, mesmo não havendo previsão expressa na CRFB, a titularidade de direitos fundamentais por parte das pessoas jurídicas é reconhecida pela jurisprudência e pela doutrina.

Não seria diferente quando se cuida acerca do direito de ver limitado o poder de tributar do Estado, pois a própria função social da empresa faz o Ente estatal se comprometer com a não interferência na iniciativa privada, chegando a impossibilitar a continuidade da atividade empresarial.

Apesar da amplitude do rol de limitações ao poder de tributar, neste estudo, buscou-se focar na igualdade, na capacidade contributiva e na proibição do confisco, com vistas a confirmar a existência do mínimo existencial da empresa na conjuntura do Direito Tributário.

Observou-se que o mínimo existencial deve ser preservado, de modo a evitar que pessoas jurídicas sejam tributadas no seu patrimônio mínimo, impossibilitando sua continuidade empresarial.

É fato, pois, que o mínimo existencial é plenamente aplicável às pessoas jurídicas, pois estas também necessitam de um patrimônio mínimo para garantir a sua existência e manutenção de sua atividade produtiva.

\section{REFERÊNCIAS}

ALEXY, Robert. Teoria dos direitos fundamentais. 2. ed. São Paulo: Malheiros, 2008.

ÁVILA, Humberto. Teoria dos princípios: da definição à aplicação dos princípios jurídicos. 5 . ed. São Paulo: Malheiros, 2006.

BRITO, Edvaldo. Reflexos jurídicos da atuação do Estado no domínio econômico. São Paulo: Saraiva, 1982.

CANOTILHO, JJ Gomes. Direito constitucional e Teoria da Constituição. 2. ed. Coimbra: Almedina, 1998. 
CAVALCANTE, Denise Lucena. A efetividade da justiça fiscal: reflexões sobre a capacidade contributiva do cidadão-contribuinte brasileiro. In: MARTINS, Ives Gandra da Silva et al (Coords.). Direito Tributário: estudos em homenagem a Edvaldo Brito. São Paulo: Atlas, 2014, pp. 266-278.

COSTA, Regina Helena. Princípio da capacidade contributiva. 4. ed. São Paulo. Malheiros, 2012.

DANIEL, Denise de Cássia. O imposto de renda das pessoas jurídicas e a compensação de prejuízos fiscais. 2006. 135 f. Dissertação de mestrado em Direito, UFPR. Curitiba: 2006.

DA SILVA, José Afonso. Curso de Direito Constitucional positivo. 40. ed. São Paulo: Malheiros, 2017.

DIMOULIS, Dimitri; MARTINS, Leonardo. Teoria geral dos direitos fundamentais. 5. ed. São Paulo: Atlas, 2014.

FACHIN, Luiz Edson. Estatuto jurídico do patrimônio mínimo - à luz do novo Código Civil Brasileiro e da Constituição Federal. 2. ed. Rio de Janeiro: Renovar, 2006.

GRUPENMACHER, Betina Treiger. Justiça fiscal e mínimo existencial. In: PIRES, Adilson Rodrigues; TORRES, Heleno Tavares (Org.). Princípios de Direito Financeiro e Tributário. Rio de Janeiro: Renovar, 2006

GODOY, Marciano Seabra. Justiça, igualdade e Direito Tributário. São Paulo: Dialética, 1999.

MAMEDE, Gladston. Empresa e atuação empresarial. 8. ed. São Paulo: Atlas, 2015.

MARTINS, Ives Gandra da Silva. Comentários à Constituição do Brasil, vol. VI. 2. ed. São Paulo: Saraiva, 2001.

MENDES, Gilmar Ferreira; BRANCO, Paulo Gustavo Gonet. Curso de Direito Constitucional. 10. ed. São Paulo: Saraiva, 2015.

SARLET, Ingo Wolfgang. A eficácia dos direitos fundamentais. 10. ed. São Paulo: Livraria do Advogado, 2009.

SCAFF, Fernando Facury. Reserva do possível, mínimo existencial e direitos humanos. In: PIRES, Adilson Rodrigues; TORRES, Heleno Tavares (Org.). Princípios de Direito Financeiro e Tributário. Rio de Janeiro: Renovar, 2006.

SCHOUERI, Luís Eduardo. Direito Tributário. São Paulo: Saraíva, 2011.

TIPKE, Klaus. Moral tributaria del Estado y de los contribuyentes. Madrid: Marcial Pons, 2002.

TIPKE, Klaus; YAMASHITA, Douglas. Justiça fiscal e princípio da capacidade contributiva. São Paulo: Malheiros, 2002.

TORRES, Ricardo Lobo. Tratado de Direito Constitucional Financeiro e Tributário. 3. ed. Rio de Janeiro: Renovar, 2005.

TORRES, Ricardo Lobo. O direito ao mínimo existencial. 2. ed. Rio de Janeiro: Renovar, 2009.

Recebido em: 21 abr. 2018.

Aceito em: 11 jun. 2018. 